\title{
IS AIRTRAQ VIDEO LARYNGOSCOPE A BETTER ALTERNATIVE TO CONVENTIONAL MACINTOSH DIRECT LARYNGOSCOPE DURING ROUTINE INTUBATION? A COMPARATIVE STUDY
}

\author{
Syed Fazal Mahmood ${ }^{1}$, S. Padmanabha ${ }^{2}$ \\ ${ }_{1}^{1}$ Post Graduate Trainee, Department of Anaesthesia, Yenepoya Medical College, Mangalore. \\ 2 Professor and HOD, Department of Anaesthesia, Yenepoya Medical College, Mangalore.
}

\begin{abstract}
The Airtraq is designed to allow visualization of the glottis without alignment of the oral, pharyngeal, and laryngeal axes. The Airtraq differs in many ways from the conventional Macintosh laryngoscope and is suiTable scope for managing anticipated/unanticipated difficult airway situations. Here tracheal intubation performance of standard Macintosh laryngoscope was compared with Airtraq in normal patients.

METHODS: Sixty patients (ASA I and II) who required surgery under general anesthesia were selected. They were randomized to intubation with the Macintosh laryngoscope or the Airtraq laryngoscope. Induction of Anaesthesia was standardized. Time taken for intubation, hemodynamic changes during intubation and ease of visualization of vocal cords (Using Cormack-Lehane grading) was compared between the groups.

RESULTS: Preoperative characteristics of the patients were similar in both groups. In the Airtraq group, tracheal intubation time using Airtraq was 10.97 seconds when compared to Macintosh laryngoscope where the time was 13.07 seconds $(\mathrm{P}=0.001)$. $\mathrm{Pulse}$ rate in both groups were in the same range before or after intubation, but change in blood pressure was more in Macintosh group $(\mathrm{P}=0.004)$. In Airtraq group all patients had Cormack-Lehane grading I, and only 2 patients had Cormack-Lehane grading of II and III in Macintosh group.
\end{abstract}

CONCLUSION: In this study, the Airtraq laryngoscope shortened the duration of tracheal intubation and provided better intubating conditions when compared with standard Macintosh laryngoscope.

KEYWORDS: Airtaq, Macintosh Laryngoscope, Intubation, Difficult Airway.

HOW TO CITE THIS ARTICLE: Syed Fazal Mahmood, S. Padmanabha. "Is Airtraq Video Laryngoscope a Better Alternative to Conventional Macintosh Direct Laryngoscope During Routine Intubation? A Comparative Study." Journal of Evolution of Medical and Dental Sciences 2015; Vol. 4, Issue 93, November 19; Page: 15903-15904, DOI: 10.14260/jemds/2015/2312.

INTRODUCTION: Difficulty or failure to intubate the trachea is an important cause of morbidity and mortality in the operative and emergency settings. ${ }^{1}$ The curved laryngoscope blade described by Macintosh remains the most widely used device to facilitate tracheal intubation. ${ }^{2}$ Intubation situations can be managed by the use of newer type of video laryngoscopes, one such is Airtraq. The Airtraq is comparatively newer, single use, laryngoscope introduced into clinical practice in 2005. The Airtraq differs in many ways from the conventional Macintosh laryngoscope and is suiTable scope for managing anticipated/unanticipated difficult airway situations. ${ }^{1}$

The Airtraq is designed to allow visualization of the glottis without alignment of the oral, pharyngeal, and laryngeal axes. Use of the Airtraq does not require displacement of the tongue and forceful elevation of the epiglottis resulting in less application of force compared with the conventional direct laryngoscopy. ${ }^{3}$ In this study tracheal intubation performance of standard Macintosh laryngoscope is compared with Airtraq in normal patients. Intubation time, hemodynamic changes and ease of visualization of glottis during intubation is compared between Airtraq and Macintosh laryngoscopes.

Financial or Other, Competing Interest: None.

Submission 28-10-2015, Peer Review 29-10-2015,

Acceptance 13-11-2015, Published 19-11-2015.

Corresponding Author:

Dr. Syed Fazal Mahmood,

Department of Anaesthesia,

Yenepoya Medical College,

Mangalore-575018.

E-mail: lazaf4u@gmail.com

DOI:10.14260/jemds/2015/2312
METHODS: Clearance from the hospital ethical committee was obtained. Written informed consent was taken from all patients; 60 patients of ASA class I and II, of age group between 18 to 65 years who required surgery under general anesthesia were included in the study. They were randomized to intubation with the Airtraq laryngoscope (Group A) and the Macintosh laryngoscope (Group M), using closed envelope method. Obese individuals, patients with anticipated difficult airway, patients with head injury, respiratory tract (Oropharynx, larynx) pathology, hiatus hernia, and pregnancy were excluded from the study.

All patients were premedicated with Tab Lorazepam $1 \mathrm{mg}$, and Tab Rantac $150 \mathrm{mg}$, two hrs. before surgery. In the operation theatre. After establishing an intravenous catheter Inj glycopyrrolate $0.2 \mathrm{mg}$ IV was given before induction of anesthesia. Standard monitors were attached; all the patients were preoxygenated with $100 \%$ oxygen for 3 minutes. Induction was done with inj fentanyl $1 \mathrm{mcg} / \mathrm{kg}$, inj propofol $2 \mathrm{mg} / \mathrm{kg}$, muscle relaxation was facilitated with inj vecuronium $0.1 \mathrm{mg} / \mathrm{kg}$, bag mask ventilation was provided with oxygen for 3 minutes.

Then tracheal intubation was performed with the Airtraq or Macintosh laryngoscope according to the randomization sequence. Time taken for intubation, hemodynamic changes during intubation and ease of visualization of vocal cords using Cormack-Lehane grading was compared between the groups. Duration of intubation attempt was defined as the time elapsed from insertion of the blade between the dental arches until the ETT was placed through the vocal cords and confirmed by auscultation. Pulse rate and Blood Pressure (SBP, DBP and MBP) was recorded before, during and after intubation in both the groups. 
Cormack-Lehane grading was used to compare the ease of visualization of vocal cords during intubation, between the groups. Statistical analysis of the results was done using student ' $\mathrm{t}$ ' test to compare intubation time and hemodynamic parameters. Chi-square test and fisher exact test was used to compare visualization of the larynx.

\begin{tabular}{|c|c|c|c|}
\hline & N & MEAN & STD deviation \\
\hline AIRTRAQ & 30 & 10.97 & 1.129 \\
\hline MACINTOSH & 30 & 13.07 & 2.97 \\
\hline \multicolumn{4}{|c|}{ Table 1: Time Taken for Intubation (In seconds) } \\
\hline
\end{tabular}

$\mathrm{P}=0.001$

Heart rate changes in both groups were in the same range before or after intubation as shown in the Table 2 .

Change in blood pressure was more in Macintosh group as shown in the Table 3.

\begin{tabular}{|c|c|c|c|c|c|c|}
\hline & $\begin{array}{c}\text { Before } \\
\text { Intubation }\end{array}$ & P-value & $\begin{array}{c}\text { During } \\
\text { Intubation }\end{array}$ & P-value & $\begin{array}{c}\text { After } \\
\text { Intubation }\end{array}$ & P-value \\
\hline $\begin{array}{c}\text { AIRTRAQ } \\
(\text { N=30) }\end{array}$ & $63.63 \pm 5.8$ & 0.754 & $67.9 \pm 5.6$ & 0.054 & $66 \pm 5.8$ & 0.409 \\
\hline $\begin{array}{c}\text { MACINTOSH } \\
(\text { N=30) }\end{array}$ & $64.13 \pm 6.49$ & & $71.47 \pm 8.1$ & & $67.4 \pm 7.1$ & \\
\hline \multicolumn{7}{|c|}{ Table 2: Heart rate changes (Beats/min) } \\
\hline
\end{tabular}

\begin{tabular}{|c|c|c|c|c|c|c|}
\hline & $\begin{array}{c}\text { Before } \\
\text { Intubation }\end{array}$ & P-value & $\begin{array}{c}\text { During } \\
\text { Intubation }\end{array}$ & P-value & $\begin{array}{c}\text { After } \\
\text { Intubation }\end{array}$ & P-value \\
\hline $\begin{array}{c}\text { AIRTRAQ } \\
\text { (N=30) }\end{array}$ & $4.27 \pm 1.74$ & 0.001 & $1.9 \pm 2.5$ & 0.004 & $2.37 \pm 2.5$ & 0.331 \\
\hline $\begin{array}{c}\text { MACINTOSH } \\
\text { (N=30) }\end{array}$ & $7.33 \pm 4.2$ & & $4.07 \pm 2.9$ & & $3.27 \pm 4.3$ & \\
\hline \multicolumn{7}{|c|}{ Table 3: Differences in Mean Blood Pressure } \\
\hline
\end{tabular}

In Airtraq group all patients had Cormack-Lehane grading I, and only 2 patients had Cormack-Lehane grading of II and III in Macintosh group each as shown in the Table 4.

\begin{tabular}{|c|c|c|c|c|}
\hline & Grade 1 & Grade2 & Grade 3 & $\begin{array}{c}\text { Grade } \\
\mathbf{4}\end{array}$ \\
\hline AIRTRAQ & $30(100 \%)$ & 0 & 0 & 0 \\
\hline MACINTOSH & $26(86.7 \%)$ & $2(6.7 \%)$ & $2(6.7 \%)$ & 0 \\
\hline \multicolumn{4}{|c|}{ Table 4: Visualization of larynx- } \\
Cormack-Lehane grading \\
\hline
\end{tabular}

DISCUSSION: Macintosh laryngoscope with its curved blade is the most commonly used device for orotracheal intubation. Airtraq is comparatively a newer intubation device. In this study the time taken for intubation using Airtraq was lesser than the time taken for intubation using Macintosh laryngoscope, which is comparable to the results in the study conducted by S. K. Ndoko et al. ${ }^{4}$ The less time taken to intubate in the Airtraq group may be due to maintaining the head in the neutral position, preloaded endotracheal tube and direct visualization of vocal cords during intubation.

Pulse rate in both the groups was in the same range before and after intubation, but change in blood pressure was more with Macintosh group as it required more force during laryngoscopy to align the oral, pharyngeal, laryngeal axes, and lifting of the epiglottis to visualize the larynx. Airtraq produces less hemodynamic stimulation, which may be an advantage in geriatrics or in patients with coronary artery disease or primary hypertension. ${ }^{5}$

In Airtraq group all patients had Cormack-Lehane grading I. In Macintosh group 2 patients had Cormack-Lehane grading II and III each. Indicating visualization of glottis by Airtraq is better. This study was conducted in adults with normal airway, and in future similar studies to be planned in patients with anticipated difficult intubations, children and obese individuals.
CONCLUSION: Airtraq laryngoscope significantly shortened the duration of tracheal intubation and provided better haemodynamic stability and good intubating conditions when compared with standard Macintosh laryngoscope.

\section{REFERENCES:}

1. J. L Tong. The management of difficult direct laryngoscopy and intubation in a field hospital: An alternative to fibreoptic endoscopy. JR Army Med Corps 2009; 153(3): 181-183.

2. Geeta Bhandari, K. S. Shahi, Mohammad Asad, Rajani Bhakuni. Airtraq versus Macintosh laryngoscope: A comparative study in tracheal intubation. Anesthesia: Essays and Researches2013; 7(2): 22-25.

3. Waleed Riad, Ashraf Moussa1, David T. Wong. Airtraq versus Macintoch laryngoscope in intubation performance in the pediatric population. Saudi Journal of Anaesthesia 2012; 6( 4): 33 -34.

4. S. K. Ndoko1, R. Amathieu, L. Tual, C. Polliand, W. Kamoun, L. El Housseini, G. Champault and G. Dhonneur. Tracheal intubation of morbidly obese patients: A randomized trial comparing performance of Macintosh and Airtraq laryngoscopes. British Journal of Anaesthesia 2008; 100 (2): 263-8.

5. Y. Lu, H. Jiang and Y. S. Zhu. Airtraq laryngoscope versus conventional Macintosh laryngoscope: A systematic review and meta-analysis. Anaesthesia 2011, 2.S. K. Ndoko66(1), 1160-67. 